\title{
Concurrent extinction does not render appetitive conditioning context specific
}

\author{
James Byron Nelson • Sebastián Lombas • \\ Samuel P. Léon
}

Published online: 2 February 2011

(C) Psychonomic Society, Inc. 2011

\begin{abstract}
In an experiment with rats, an appetitive conditioning method was used to investigate the generality of the hypothesis that extinction should arouse attention to contextual cues, resulting in all learning in that context becoming context specific. Rats received appetitive conditioning with a tone either while extinction of a flasher occurred (Group With Extinction) or while it did not (Group No Extinction). Half of each group was subsequently tested in extinction in the context in which training had taken place or in a different context. The results revealed a three-way interaction of extinction and context with trials, in a direction opposite to the one the hypothesis would suggest. When rats were tested in a different context, there was generally better responding in Group With Extinction than in Group No Extinction. In the same context, there was generally lower responding in Group With Extinction than in Group No Extinction. Subsequent testing showed an ABA recovery effect. Results are discussed in terms of the challenges they pose for the revised retrieval theory presented by Callejas-Aguilera and Rosas (2011).
\end{abstract}

\footnotetext{
J. B. Nelson · S. Lombas

University of the Basque Country,

San Sebastian, Spain

S. P. Léon

University of Jaén,

Jaén, Spain

J. B. Nelson ( $\varangle)$

Depto. Procesos básicos y su desarrollo,

Universidad de País Vasco,

Avenida de Tolosa, 70,

San Sebastián, Spain 20018

e-mail: JamesByron.Nelson@Ehu.es
}

Keywords Associative learning · Extinction - Renewal . Attention

Rosas and Callejas-Aguilera (2006) demonstrated that when extinction is conducted with one cue, subsequent conditioning to other cues becomes context specific. In a computerbased predictive-learning task, participants associated food cues with outcomes such as gastric malaise in the context of particular restaurants. Knowledge that a particular food cue consistently predicted the same outcome transferred well to different contexts. However, if an outcome was changed between phases for one food cue, information about other food cues, which had not changed, became sensitive to the restaurant context. That is, when the original learning about one cue was replaced with learning about a new outcome, learning about any other cue became context specific.

Rosas and Callejas-Aguilera's (2006) results appear well established within their methodology (see also Nelson \& Callejas-Aguillera, 2007; Rosas, Callejas-Aguilera, RamosÁlvarez, \& Abad, 2006) and are consistent with their "attentional theory of context processing." In that theory, they assume that whenever attention is devoted to contextual cues, learning in those contexts will be context dependent. They further specify that the presentation of "ambiguous" stimuli, such as those that have undergone conditioning and extinction, will lead participants to attend to the context. Like Bouton (1997), they assume that, when a stimulus undergoes extinction, it has two possible meanings (e.g., unconditioned stimulus [US] and no US) and that attention is aroused to the context to disambiguate those meanings. Unlike Bouton (1997), Rosas and Callejas-Aguilera (2006) assume that once attention is aroused to the context, all subsequent learning in that context will be contextually controlled. The control is not limited to the stimulus that supposedly arouses the attention. 
Their theory adequately captures their result and also provides an explanation for the renewal effect, the recovery of an extinguished conditioned response (CR) as the result of a change in the background context in which extinction took place. Following conditioning, a conditioned stimulus (CS) is presented without the US in extinction, which diminishes the $\mathrm{CR}$. When the extinguished CS is tested in a context other than that in which extinction occurred, the CR is typically recovered (e.g., Rescorla, 2008). The effect is not limited to conditioning and extinction but appears to represent a more general principle (Bouton, 2004) whereby second-learned associations are observed to be sensitive to changes in context (Nelson, 2002, 2009), especially when they interfere with earlier learning (Nelson \& Callejas-Aguillera, 2007).

The application of their theory to renewal is straightforward. Extinction is supposed to arouse attention to the context as the stimulus becomes ambiguous, resulting in the extinction learning becoming context specific. Due to the broad relevance of the renewal effect to other phenomena in associative learning and psychology (for discussions, see Bouton, 1993, 2000, 2004; Nelson, Sanjuan, Vadillo-Ruiz, Perez, \& Leon, 2011), the theory of Rosas and CallejasAguilera (2006) is potentially of broad scope. Yet demonstrations of the main prediction of the theory have been clearly obtained only in predictive-learning tasks with humans. Thus, the general applicability of the theory has yet to be established.

Work on this question with animals currently consists of one brief report. Rosas and Callejas-Aguilera (2007) trained one group of rats in a taste aversion procedure in which flavor X was paired with a lithium-chloride-induced illness in context $\mathrm{A}$. In the second phase, the aversion to $\mathrm{X}$ was extinguished. Here, attention should be aroused to the context, and any subsequent learning in that context should be context specific. After the aversion to $\mathrm{X}$ was extinguished, a new flavor, Y, was conditioned. A control group received the same training, except that, in the first phase, $\mathrm{X}$ and the lithium-chloride-induced illness were not paired. Since $\mathrm{X}$ was not conditioned in the latter group, $\mathrm{X}$ did not undergo extinction in the second phase, and attention should not have been aroused to the context. When tested between subjects in context $\mathrm{A}$ or in context $\mathrm{B}$, there was a loss of the aversion to $\mathrm{Y}$ with the context change in the group in which $\mathrm{X}$ had undergone extinction. Such a loss was not evident in the groups in which $\mathrm{X}$ did not undergo extinction.

Although these results are suggestive, we should be cautious about their interpretation. Although it is not always the case (e.g., Rosas \& Bouton, 1997, 1998), taste aversion learning has sometimes been shown to be context specific (see Archer, Sjödén, \& Nilsson, 1985; Bonardi, Honey, \& Hall, 1990; Sjödén \& Archer, 1989). Thus, one could argue that something about Rosas and Callejas-Aguilera's (2006) unpaired control treatment reduced the context specificity that would ordinarily have been observed, rather than saying that the experimental treatment produced it. Also, although not analyzed, there appears to have been less of an aversion in context $\mathrm{A}$ in the control group than in the experimental group, reducing the range in which it was possible to observe an effect. Finally, Rosas and Callejas-Aguilera's (2006) analysis strategy did not directly assess the effect of their between-group extinction manipulation. They did not directly show that extinction had an effect when testing occurred in a different context and none when testing occurred in the same context. Rather, they demonstrated a context effect in groups that had experienced extinction, but not in controls. The goal of the present experiments was to determine whether extinction of one stimulus would lead to the context specificity of another in rats, using a conditioning preparation where conditioned responding has been shown to transfer well across contexts (e.g., Brooks \& Bouton, 1994; Nelson, 2002; Nelson \& Bouton, 1997).

In the experiment, rats received appetitive conditioning with a flashing light-emitting diode (LED) stimulus. Then they were divided into two groups that received conditioning with a tone ( $\mathrm{T})$. In Group With Extinction, $\mathrm{T}$ was conditioned during sessions in which the flashing LED stimulus was presented without the US. In Group No Extinction, T was conditioned during sessions with no other events occurring. Finally, half of each group was tested in context $\mathrm{B}$, and the other half was tested in context $\mathrm{A}$, the context of training. The two contexts were equally familiar and equally associated with the food US. If extinction arouses attention to the context, leading to all information being encoded as context specific, there should be less responding to $\mathrm{T}$ in context $\mathrm{B}$ by Group With Extinction than by Group No Extinction.

\section{Method}

\section{Subjects}

Thirty-two male Wistar rats with an average weight of $367 \mathrm{~g}$ were used in this experiment. Rats were housed in stainless steel hanging cages on a 12:12-h light:dark cycle. The experiment was conducted in the light part of the cycle. Water was available ad lib. Access to food was restricted as described below. These rats had previously served in a taste aversion experiment in their home cages.

\section{Apparatus}

All the experimental equipment was contained in sound attenuation chambers. The inside of each chamber was square $(\mathrm{W}=\mathrm{H}=54 \mathrm{~cm})$, and the chamber was $39 \mathrm{~cm}$ deep. A $12.5-\mathrm{cm} 8-\mathrm{ohm}$ speaker was mounted on the right wall at 
a height of $34 \mathrm{~cm}$ and $18 \mathrm{~cm}$ from the rear wall. A $12-\mathrm{V}$ light was mounted in the ceiling of the chamber in a $12 \times 6 \times 3 \mathrm{~cm}$ $(\mathrm{L} \times \mathrm{W} \times \mathrm{H})$ plastic diffusing prism. The prism was mounted with the length parallel to the rear wall, $18 \mathrm{~cm}$ from the rear wall and $10 \mathrm{~cm}$ from the right wall. A $7.5-\mathrm{cm}$-square ventilation fan was mounted in the lower left corner of each chamber, which provided $60 \mathrm{db}$ of background noise.

Each sound attenuation chamber housed an operant testing box (MED Associates ENV-007). Each box was placed in an attenuation chamber $18 \mathrm{~cm}$ from the right wall and $8 \mathrm{~cm}$ from the rear wall, so that the right panel of the boxes, which contained visual light stimuli, was shadowed.

The front, back, and top of each $30.5 \times 24.1 \times 29.2-\mathrm{cm}$ $(\mathrm{L} \times \mathrm{W} \times \mathrm{H})$ box was Plexiglas, with the right and left walls constructed of aluminum with grid floors. Bars in the floor were $3 \mathrm{~mm}$, spaced $1 \mathrm{~cm}$ apart. The right wall of each box contained nonauditory stimuli. A food delivery magazine with a $5 \times 5 \mathrm{~cm}$ square opening and a depth of $4 \mathrm{~cm}$ was centered from left to right in the wall and mounted so that the food trough was $5 \mathrm{~cm}$ above the grid floor. A photocell was mounted $1 \mathrm{~mm}$ above the trough at a depth of $1 \mathrm{~cm}$. Two white $28-\mathrm{V}$ key lights $(2.5-\mathrm{cm}$ diameter $)$ were mounted $18 \mathrm{~cm}$ above the grid floor and $7 \mathrm{~cm}$ horizontally to the left and right of the center of the wall. Three 5-mm LEDs were mounted $4 \mathrm{~cm}$ above the food magazine, with the second centered in the wall from left to right and the other two mounted $1 \mathrm{~cm}$ to the left or right of the center. The leftmost LED was red, the center one was yellow, and the rightmost LED was green.

When delivered, the tone stimulus ( $\mathrm{T}$ ) was an $80-\mathrm{db}$ $3000-\mathrm{Hz}$ tone through the speaker. The illumination of the key light mounted to the left of the food cup served as stimulus L. Each LED was illuminated in turn from left to right in a flashing sequence. For example, the first LED was illuminated for $20 \mathrm{~ms}$, producing a flash. As that LED was turned off, the middle LED was flashed on, and so forth, with the illumination of the leftmost LED following that of the rightmost LED. This flashing sequence of LEDs served as stimulus F. All the stimuli were $10 \mathrm{~s}$ in duration. When delivered, the US was the delivery of two $45-\mathrm{mg}$ pellets (PJ Noyes traditional formula), immediately on termination of the CS.

The eight operant boxes were divided into two sets of four. One set of boxes had a laminated solid-white sheet of paper located behind the rear Plexiglas wall so that it appeared uniformly white. The bars in the floor of these boxes were mounted parallel to each other at the same height. The other set of four boxes differed from the first in visual and tactile respects. The sheet of paper mounted outside the rear wall had a checkerboard pattern with $2.5-\mathrm{cm}$ black and white squares. The grid floor consisted of staggered grids with odd-numbered grids mounted $1 \mathrm{~cm}$ above the evennumbered grids. These two sets of boxes served as contexts A and B and were always completely counterbalanced. For half the rats, context $\mathrm{A}$ was provided by the boxes with the white back wall, and context B was provided by the boxes with the checkered back wall. That assignment was reversed for the other half of the rats.

All events were controlled by a Pentium (IBM-compatible) computer programmed in Pascal. Photocells were sampled over 1,700 times per second.

\section{Procedure}

Rats were food deprived over 1 week to $80 \%$ of their freefeeding weight and were maintained at that weight throughout the experiment. On the first day of training, the rats were placed in both sets of boxes for $30 \mathrm{~min}$ in each session. During the first $15 \mathrm{~min}$, they were allowed to explore the chambers, with no events occurring. During the last $15 \mathrm{~min}, 20$ single food pellets were delivered with a variable 45-s schedule to train the rats to eat from the food cup at the sound of a pellet delivery. Intersession intervals were approximately $2.5 \mathrm{~h}$.

All the rats received two 60-min sessions of training each day for the remainder of the experiment, with an intersession interval of approximately $4.5 \mathrm{~h}$. Throughout the experiment, excluding the test days, there was one session in context $\mathrm{A}$ and one in context $\mathrm{B}$, in order to equate familiarity with the two contexts. Every session in B included a pairing of $\mathrm{L}$ with the US at the same time into the session as the US occurred in the corresponding session in context $\mathrm{A}$. The order of exposure was $\mathrm{ABAB}$ or $\mathrm{BABA}$, varying daily with the restriction that each experimental phase began in context A. There were two phases of training and a test.

Phase 1: Excitatory conditioning of $F$ Each daily session of phase 1 in context A contained 10 pairings of $F$ with the US, with an intertrial interval (ITI) varying randomly around a mean of $350 \mathrm{~s}$. There were 6 days of training in the first excitatory-conditioning phase.

Phase 2: Excitatory conditioning with or without extinction The rats were divided into two groups of 16 by matching them on their performance to $\mathrm{F}$ in the previous phase. Over the next 3 days, the rats in Group With Extinction received five trials with $\mathrm{F}$ presented without the US and five trials with $\mathrm{T}$ paired with the US in each daily session. The first session began with three presentations of $F$. The sequence for the remainder of the trials and the remaining sessions was randomly determined, with the restriction that no more than two trials of a type should occur together. The ITIs were randomly determined, with an average of $350 \mathrm{~s}$. Rats in Group No Extinction received the same $\mathrm{T}+$ trials, distributed across the session in the same way as for those 
in Group With Extinction, but there were no stimuli presented on trials where $\mathrm{F}$ would have occurred in Group With Extinction.

\section{Testing}

Test of the context specificity of conditioning An apparatus failure on day 2 of the first phase corrupted one squad of rats, leaving only 12 rats per condition. Following the last day of the second phase, each group of 12 was subdivided into two matched groups of 6 on the basis of performance prior to the test. One group of 6 rats from each main group received a test in context $\mathrm{A}$, and the other in context $\mathrm{B}$. Each group was tested twice in its assigned context. On each test, there were 10 presentations of $\mathrm{T}$ in extinction, using the same ITI and interstimulus interval schedules as those used in the previous phase.

Having extensive experience with this method, we knew that that number of rats per group $(n=6)$ would be too small to reliably detect any but the largest of effects. Thus, we immediately replicated the study with 32 more rats with the same characteristics as those in this study (average weight, $375 \mathrm{~g}$ ), raising the overall $n$ per condition to 14 .

Test of context specificity of extinction In the replication, following the last day of the test of context specificity of conditioning, both groups of rats received another session of further testing to assess whether conditioned responding would recover when the CS was tested outside the extinction context. All the rats received a recovery test in context A, where they received 10 trials with $\mathrm{T}$ in extinction. The parameters of the test were the same as those in the test of context specificity of conditioning. Groups that received the previous test with $\mathrm{T}$ in context $\mathrm{B}$ in extinction were expected to show an $\mathrm{ABA}$ recovery effect (e.g., Brooks \& Bouton, 1994).

\section{Data and analysis}

A computer recorded the number of times the photocell in the food cup was interrupted during the 10-s CSs and during the 10-s immediately prior to the CS (pre-CS). All data were analyzed with a mixed-factorial analysis of variance (ANOVA) with Type III sums of squares. Simple effects were conducted using an ANOVA with error terms appropriately derived from the overall analysis, using standard methods (see Howell, 1987). Degrees of freedom for simple effects were reduced, using the Welch (1938)Satterthwaite (1946) procedure to compensate for the pooling of potentially heterogeneous variances. Analyses of the number of trials on which one group outperformed another on the test were analyzed with binomial tests.
In the analysis of responding in the CS, effect sizes were computed for the overall ANOVAs, using partial eta squared $\left(\eta_{\mathrm{p}}{ }^{2}\right)$. For analyses of the test that involved only two means, Cohen's $d\left(\bar{X} 1-\overline{X 2} / \sqrt{S_{\text {pooled }}^{2}}\right)$ was calculated, using the respective variances of the variables being compared. Throughout, a rejection criterion of $p<.05$ was adopted, although exact probabilities were reported to provide a full characterization of the results.

\section{Results}

Phase 1: Conditioning with $\mathrm{F}$

Responding to F increased over sessions The six sessions of conditioning with $\mathrm{F}$ were analyzed with an extinction (with or without) $\times$ test context $(\mathrm{A}$ or $\mathrm{B}) \times$ session ANOVA, which showed a reliable effect of session, $F(5,260)=$ 12.64, $p<.001, \eta_{\mathrm{p}}{ }^{2}=.19$, and no other effects or interactions, $F \mathrm{~s} \leq 1.13, p \mathrm{~s} \geq .57$. The data are shown in the left of Fig. 1, which collapses across the insignificant grouping variables. The same analysis of pre-CS responding showed an effect of trials, $F(5,260)=16.05, p<.001$, since pre-CS responding decreased from a mean of 2.1 to a mean of 0.7 over the sessions. There were no other effects in the pre-CS analysis, $F \mathrm{~s} \leq 1.4, p \mathrm{~s} \geq .22$.

Phase 2: Conditioning of $\mathrm{T}$ with or without extinction of $\mathrm{F}$

Conditioning of $T$ Responding to $\mathrm{T}$ increased over sessions and was unaffected by whether or not it was conducted concurrently with extinction of F. Conditioning trials with $\mathrm{T}$ were analyzed with an extinction $\times$ test context $\times$ trials $\times$ session ANOVA. The analysis revealed effects of session, $F(2,104)=42.22, p<.001, \eta_{\mathrm{p}}{ }^{2}=.45$, and trials, $F(4,208)=49.35, p<.001, \eta_{\mathrm{p}}{ }^{2}=.49$, and a session $\times$ trials interaction, $F(8,416)=5.26, p<.001$, $\eta_{\mathrm{p}}{ }^{2}=.098$. There were effects of trials within each session, $F \mathrm{~s}(4,622)=20.37,28.2$, and 15.30 , for sessions 1,2 , and 3 , respectively. The effect of trials was simply more pronounced in the first session and smaller by the third session. These data are shown in Fig. 1 as the circles (Group With Extinction) and squares (Group No Extinction) above "T+/- or F-" on the abscissa, collapsed across trials.

There were no other reliable effects, although the session $\times$ trials $\times$ context interaction approached significance, $F(8$, $416)=1.76, p=.08$. The groups were formed by matching on the session means. The matching did not consider the distribution of the trials within each session, yet inspection of the data did not reveal any obvious patterns that would suggest a trials $\times$ context interaction. Any preexisting difference here would be important on the test, so we 


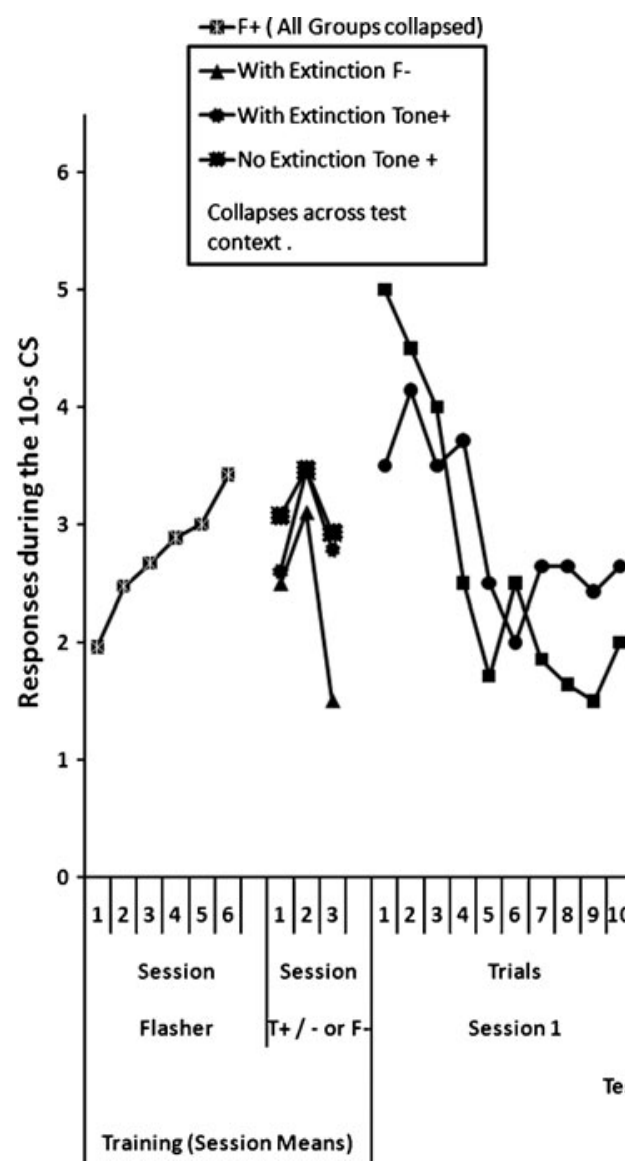

Fig. 1 Responding during the conditioned stimulus (CS). Leftmost points show session means of responding to $\mathrm{F}$ in the first phase, collapsed across groups. Points above " $\mathrm{T}+/$ - or F-" show session means of responding to $\mathrm{T}$ when conditioned alone in Group No Extinction (squares) or during extinction of $\mathrm{F}$ in Group With

conducted simple-effect tests of context on each trial of each session and found no differences, $F_{\mathrm{S}}<1$.

The same analysis of pre-CS responding before $\mathrm{T}$ trials revealed an extinction $\times$ session interaction, $F(2,104)=4.90$, $p=.009$. On the first session, responding appeared lower for the groups receiving extinction of $\mathrm{F}(M=0.46)$ than for those in the other condition $(M=1.26), F(1,145)=8.96, p=.004$. The differences were more negligible and unreliable, $F_{\mathrm{S}}<1$, on the last two sessions (session 2, $M=0.8$ and 0.82 for Groups With Extinction and No Extinction, respectively; session 3, $M=0.82$ and 0.68 for Groups With Extinction and No Extinction, respectively). We will have more to say about these differences in the Discussion section.

Extinction of $F$ Responding to $F$ declined over sessions in the group that received extinction. Extinction trials with $\mathrm{F}$ were analyzed with a test context $\times$ trials $\times$ session ANOVA. The analysis revealed effects of trials, $F(4,104)=2.68, p=.035$, $\eta_{\mathrm{p}}^{2}=.09$, and session, $F(2,52)=10.52, p<.001$, $\eta_{\mathrm{p}}^{2}=.29$, and a trials $\times$ session interaction, $F(8,208)=$ $3.71, p<.001, \eta_{\mathrm{p}}{ }^{2}=.13$. Responding tended to decrease

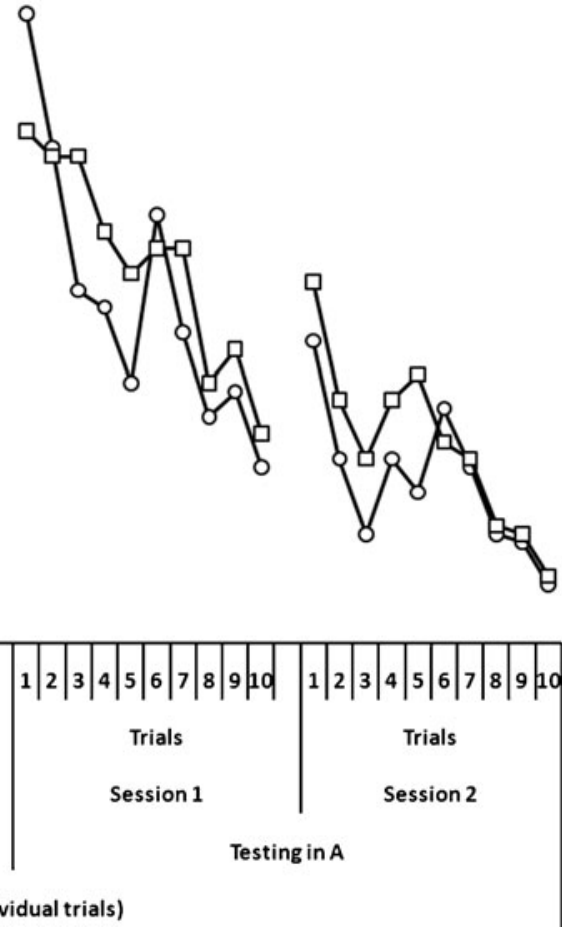

Testing (individual trials)

Extinction (circles). Triangles show responding to $\mathrm{F}$ during extinction. Solid symbols above "Test T-" show the individual trials of each test session in context B, while open symbols on the far right show the individual test trials of test each session in context $\mathrm{A}$. See the text for further details

across trials in session 1, perhaps showed some spontaneous recovery in session 2 , and decreased across trials again in session 3. No other effects were reliable, $F \mathrm{~s} \leq 1.30, p \mathrm{~s} \geq .27$. These data are shown in Fig. 1 as the triangles above "T+/- or F-" on the abscissa, collapsed across the trials.

The same analysis of pre-CS responding (the number of responses in the $10 \mathrm{~s}$ prior to CS onset) showed a session $\times$ trials interaction, $\mathrm{F}(8,208)=2.13, p=.03$. The interaction was due to some minor variability among the trials in the first session $($ minimum $=0.21$ on trial 2 , maximum $=1.1$ on trial 3) and second session (minimum $=0.18$ on trial 2, maximum $=1.32$ on trial 4 ) that was absent by the third session (minimum $=0.32$ on trial 2 , maximum $=0.57$ on trial 3).

Test

Context specificity of conditioning The first session was analyzed with an extinction (conditioning was concurrent with extinction of another stimulus or was not) $\times$ context $x$ trials ANOVA. The analysis revealed an effect of trials, 
$F(9,468)=15.23, p<.001, \eta_{\mathrm{p}}{ }^{2}=.23$, and an extinction $\times$ context $\times$ trials interaction, $F(9,468)=2.18, p=.02$, $\eta_{\mathrm{p}}{ }^{2}=.04$. There were no other effects, $F_{\mathrm{s}}<1$. The analysis was a rare case in which the interaction test had more power than the direct simple-effect tests. There was no detectable simple effect of the extinction manipulation in either test context. When tested in context B, there was a trend for responding on trial 1 to be higher in Group No Extinction than in Group With Extinction, $F(1,253)=3.37$, $p=.068$. No other comparison of Group With Extinction with Group No Extinction in either context approached significance $F \mathrm{~s} \leq 1.5, p \mathrm{~s} \geq .22$.

We further examined the three-way interaction by comparing the difference obtained between the two extinction groups in each context ([With Extinction, context B minus No Extinction, context B] vs. [With Extinction, context A minus No Extinction, context A]) on each trial. That is, we investigated extinction $\times$ context interactions on each trial. We found that the pattern produced by the extinction manipulation in context $\mathrm{B}$ was significantly opposite that produced in context A on trials 1, 3, and 4, $F \mathrm{~s}(1,253) \geq 4.4, p \mathrm{~s} \leq .037$, and it approached significance on trial $7, F(1,253)=3.37, p=.068$.

The same ANOVAs applied to pre-CS responding showed an effect of trials, $F(9,468)=2.35, p=.01$, and no other effects, $F \mathrm{~s}<1$. Responding decreased from an initial mean of 0.89 to 0.39 across the test session.

An extinction $\times$ context $\times$ trials ANOVA of responding to the $\mathrm{CS}$ on the second session produced only an effect of trials, $F(9,468)=7.21, p<.001, \eta^{2}=.12$, and no other effects, $F \mathrm{~s} \leq 1.88, p \mathrm{~s} \geq .18$. The same analysis of pre-CS responding on session 2 showed no effects, $F_{\mathbf{S}}<1$. Pre-CS responding averaged 0.42 on session 2 of the test.

When tested in context $\mathrm{B}$, rats that received conditioning of $\mathrm{T}$ concurrent with extinction of $\mathrm{F}$ responded at a numerically higher rate on the majority of the trials (15 of 20) than did those that simply received conditioning of $T$ (binomial $p=.01$ ). In context $\mathrm{A}$, the pattern was reversed. Rats that received conditioning of $\mathrm{T}$ concurrent with extinction of $\mathrm{F}$ responded numerically less on the majority of trials than did those that simply received conditioning of $\mathrm{T}$ on 16 of 20 trials (binomial $p=.005$ ). During the pre-CS, rats in Group With Extinction responded numerically more than did rats in the other condition on 9 of 20 trials in context $\mathrm{B}$ and on 11 of 20 trials in context $\mathrm{A}$, and neither pattern was reliable, (binomial $p \mathrm{~s}=.116$ ). These binomial analyses further suggest that any effect of context that might be inferred from these data is in a direction opposite to the findings of Rosas and Callejas-Aguilera (2006).

Context specificity of extinction Data from the 32 rats in the replication that received a recovery test are shown in Fig. 2. The points in the left panel show responding collapsed

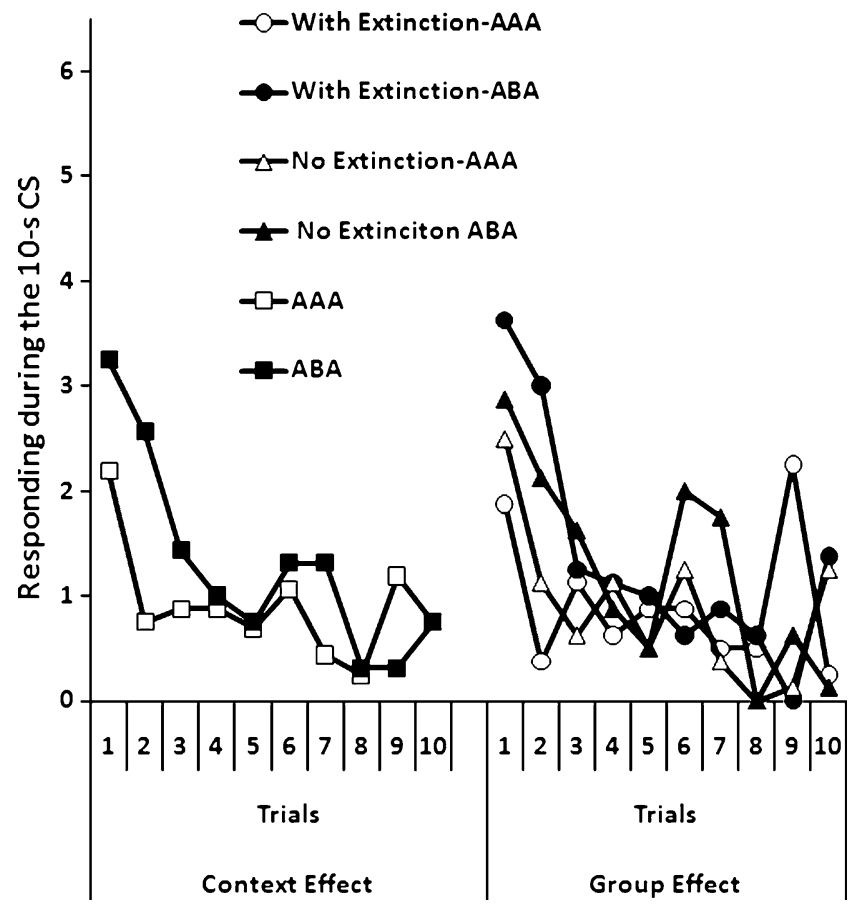

Fig. 2 Responding during the conditioned stimulus (CS) in context A on the first recovery test. Leftmost points show responding collapsed across the extinction variable. Rightmost points show responding in all four groups without collapsing. Groups received conditioning while another stimulus was concurrently undergoing extinction (Group With Extinction) or while one was not (Group No Extinction). Letters after group names refer to the context in which $\mathrm{T}$ was trained, first tested (and extinguished), and retested for recovery. See the text for details

across the extinction variable to show only the effect of context, while the points in the right panel show responding in all four groups without collapsing. Rats whose responding was extinguished in the first test in context B showed a recovery of responding when tested in context $\mathrm{A}$. The extinction manipulation had no effect on that recovery.

The description above was confirmed by an extinction $\times$ context (testing of $\mathrm{T}$ in extinction in context $\mathrm{A}$ or $\mathrm{B}$ in the first test $) \times$ trials ANOVA. There were effects of trials and context $\times$ trials and extinction $\times$ context $\times$ trials interactions, $F_{\mathrm{S}}(9,252) \geq 2.25, p \mathrm{~s} \leq .02, \eta^{2}=.07$. The context $\times$ trials interaction is shown at the left in Fig. 2. The groups that received extinction in $\mathrm{B}$ responded more on the test than did those extinguished in $\mathrm{A}$ on trials 1 and $2, F \mathrm{~s}(1$, $260)=4.07(p=.04)$ and $11.85(p=<.001)$, respectively. There were no further differences, $F \mathrm{~s} \leq 2.76, p \mathrm{~s} \geq .098$. The three-way interaction (see Fig. 2, right) was due to a difference on trial 9 between Groups With Extinction and No Extinction that received the first test in context A, $F(1$, $260)=8.14, p=.005$. As is shown in the figure, that difference was the result of what appeared to be a spurious high rate of responding for Group With Extinction. There were no differences between Groups With Extinction and 
No Extinction when tested in context A on any other trial or in context $\mathrm{B}, F_{\mathrm{s}}(1,260) \leq 3.41, p \mathrm{~s} \geq .07$. The same analysis of the data with trial 9 excluded removed the three-way interaction, showing only effects of trials $F(8,224)=8.38$, $p<.001, \eta^{2}=.23$, and context, $\mathrm{F}(1,28)=5.54, p=.03, \eta^{2}=$ .17 . No other effects were reliable, $F_{\mathrm{S}} \leq 1.56, p \mathrm{~s} \geq .14$. The same analysis of pre-CS responding showed no effects, $F_{\mathrm{S}} \leq$ 1. Responding in the pre-CS averaged 0.3 during the test.

\section{Discussion}

The experiment determined whether the hypothesis and findings put forth by Rosas and Callejas-Aguilera (2006) would hold in an appetitive-conditioning method with rats. After receiving conditioning of $\mathrm{T}$ either while another CS was undergoing extinction or while it was not, all the rats were tested for context specificity of responding to $\mathrm{T}$ in another context. Contrary to the hypothesis, there was no evidence of a decrement in responding to $\mathrm{T}$.

Extinction of $\mathrm{F}$ occurred in all sessions in which $\mathrm{T}$ was being conditioned in Group With Extinction. The analysis of the extinction of $\mathrm{F}$ showed that there were effects of session as responding decreased between sessions and that there was an effect of trials as responding decreased within each session. Performance to F changed over sessions; thus, it should have been ambiguous in meaning. According to both Rosas and Callejas-Aguilera (2006) and Darby and Pearce (1995), attention should have been present within each session, ensuring that the conditioning to $\mathrm{T}$ was context specific, producing a decrement in responding with a context change.

If anything, extinction appeared to have generally opposite effects on responding, depending on the context in which testing occurred. On the first trial, the pattern elicited in context B was the opposite of that in context A. In context $\mathrm{B}$, concurrent extinction appeared to lead to a reduction in responding, and in context $\mathrm{A}$, it appeared to lead to an increase in responding. That pattern alone could be consistent with the hypothesis of Rosas and CallejasAguilera (2006), but the opposite pattern was obtained on trials 3 and 4 and was almost reliable on trial 7. The binomial analysis of the directionality of responding was also consistent with the idea that responding transferred better to context $\mathrm{B}$ when it was acquired concurrently with extinction. Thus, the overall pattern was more consistent with the idea that conditioned responding transferred exceptionally well when it was acquired concurrently with extinction.

We can only speculate as to why that unexpected pattern may have occurred. The overall pattern obtained might be explained if the context were to become weakly inhibitory during the second phase in Group With Extinction. The extinction trials with $\mathrm{F}$ could produce a small amount of inhibition to the context, which could mildly supercondition T (e.g., Williams \& McDevitt, 2002). Such conditioning would be revealed as an increase in responding to $T$ in context B. Also, the presence of weak inhibition to the context might facilitate extinction in that group when conducted in context A. The pre-CS analysis of the second phase was consistent with this speculation. On the first session, where the excitatory $\mathrm{F}$ began extinction, there was less baseline responding before $\mathrm{T}$ trials in Group With Extinction than in Group No Extinction. Although that difference disappeared on later sessions, it was nevertheless consistent with the idea that some weak inhibition may have been present to the context following F trials in Group With Extinction.

Data from the recovery test confirmed that the rats discriminated the contexts. Rats that were initially tested and extinguished in context B showed a recovery of responding when tested back in context A. Learning about T concurrently with the extinction of $\mathrm{F}$ did not affect that recovery.

The theory put forth by Rosas and Callejas-Aguilera (2006) has undergone some revision (Callejas-Aguilera \& Rosas, 2011; Rosas et al. 2006) since its initial presentation (Rosas, García-Gutiérrez, \& Callejas-Aguilera, 2006). Initially, the theory suggested that attention might engage the context through a modulator-type mechanism such as that offered by Bouton (1993), or that the context may act as an occasion setter, or that the context could enter into a configural cue such as that proposed by Pearce (1987, 1994). Most recently, Callejas-Aguilera and Rosas stated that attention could lead to the use of the mechanisms just mentioned, as well as direct context-outcome associations, which we may have observed as inhibition conditioned to the context in the second phase.

Considering that their theory is still in development, these results produce important constraints on their theorizing. Our results show that making $\mathrm{F}$ ambiguous through extinction did not lead to context specificity of conditioned responding to $\mathrm{T}$. The extinction of $\mathrm{F}$ did appear to engage some mechanism, since it was not completely without effect on T. The context switch tended to increase responding to $T$ when it was conditioned concurrently with extinction of $\mathrm{F}$. Whether the results we obtained were due to some mild inhibition to the context is speculation, as is whether or not attention to the context (induced by extinction of the flasher) would lead to the development of that type of direct context-outcome association. The theory does not presently define the conditions under which the supposed attention should promote the operation of one mechanism (e.g., modulation) over another (e.g., contextoutcome associations).

We believe that two things must be accomplished for the theory of Rosas and his colleagues to continue to warrant 
serious attention. First, we believe that empirical work should demonstrate the involvement of attention. To date, there has been no independent evidence of attention beyond the effects it has been invoked to explain, a point Rosas and Callejas-Aguilera (2006) acknowledged. Second, the most recent exposition of the theory must be refined so that clear a priori predictions regarding when attention will favor one mechanism of contextual control over another can be determined. Callejas-Aguilera and Rosas (2011) have predicted an effect of a context change in these experiments, yet without further clarifications, the direction of that change cannot be specified. In the absence of that clarification, the present results are at strong odds with the one clear hypothesis offered by the theory that has been demonstrated with humans, challenging the theory's present usefulness as a general principle.

Acknowledgements The research and report presented here were made possible by a Ramón y Cajal fellowship (RYC2005-447) awarded to the first author, which was funded in part by the Fondo Social Europeo. Preparation of the manuscript was also supported by Grants IT-276-07 from the Basque Ministry of Science and PSI200800412/PSIC from the Spanish Ministry of Science and Innovation. Participation in the research by Samuel P. Léon was enabled by Projects SEJ2007-67053/PSIC and BES-2008-003634 from the Spanish Ministry of Science and Innovation. The technical and human support provided by SGIker (UPV/EHU, MICINN, GV/EJ, ESF) is gratefully acknowledged.

\section{References}

Archer, T., Sjödén, P., \& Nilsson, L. (1985). Contextual control of taste aversion conditioning and extinction. In P. D. Balsam \& A. Tomie (Eds.), Context and learning (pp. 225-271). Hillsdale: Erlbaum.

Bonardi, C., Honey, R. C., \& Hall, G. (1990). Context specificity of conditioning in flavor-aversion learning: extinction and blocking tests. Animal Learning \& Behavior, 18, 229-237.

Bouton, M. E. (1993). Context, time, and memory retrieval in the interference paradigms of Pavlovian learning. Psychological Bulletin, 114, 80-99.

Bouton, M. E. (1997). Signals for whether versus when an event will occur. In M. E. Bouton \& M. S. Fanselow (Eds.), Learning, motivation and cognition: The functional behaviourism of Robert C. Bolles (pp. 385-409). Washington: American Psychological Association.

Bouton, M. E. (2000). A learning theory perspective on lapse, relapse, and the maintenance of behavior change. Health Psychology, 19, 57-63.

Bouton, M. E. (2004). Context and behavioral processes in extinction. Learning \& Memory, 11, 485-494.

Brooks, D. C., \& Bouton, M. E. (1994). A retrieval cue for extinction attenuates response recovery (renewal) caused by a return to the conditioning context. Journal of Experimental Psychology: Animal Behavior Processes, 20, 366-379.

Callejas-Aguilera, J. E., \& Rosas, J. M. (2011). Ambiguity and context processing in human predictive learning. Journal of
Experimental Psychology: Animal Behavior Processes, 36(4), 482-494.

Darby, R. J., \& Pearce, J. M. (1995). Effects of context on responding during a compound stimulus. Journal of Experimental Psychology: Animal Behavior Processes, 21, 143-154.

Howell, D. C. (1987). Statistical methods for psychology. Boston: Duxbury.

Nelson, J. B. (2002). Context specificity of excitation and inhibition in ambiguous stimuli. Learning and Motivation, 33, 284-310.

Nelson, J. B. (2009). Contextual control of first- and second-learned excitation and inhibition in equally ambiguous stimuli. Learning \& Behavior, 37, 95-106.

Nelson, J. B., \& Bouton, M. E. (1997). The effects of a context switch following serial and simultaneous feature-negative discriminations. Learning and Motivation, 28, 56-84.

Nelson, J. B., \& Callejas-Aguillera, J. E. (2007). The role of interference produced by conflicting associations in contextual control. Journal of Experimental Psychology: Animal Behavior Processes, 33, 314-326.

Nelson, J. B., del Carmen Sanjuan, M., Vadillo-Ruiz, S., Pérez, J., \& León S. P. (2011). Experimental renewal in human participants. Journal of Experimental Psychology: Animal Behavior Processes (In press).

Pearce, J. M. (1987). A model for stimulus generalization in Pavlovian conditioning. Psychological Review, 94, 61-73.

Pearce, J. M. (1994). Similarity and discrimination: a selective review and a connectionist model. Psychological Review, 101, 587-607.

Rescorla, R. A. (2008). Within-subject renewal in sign tracking. Quarterly Journal of Experimental Psychology, 61, 1793-1802.

Rosas, J. M., \& Bouton, M. E. (1997). Renewal of conditioned taste aversion upon return to the conditioning context after extinction in another one. Learning and Motivation, 28, 216-229.

Rosas, J. M., \& Bouton, M. E. (1998). Context and retention interval can have additive, rather than interactive, effects after taste aversion conditioning. Psychonomic Bulletin \& Review, 5, 79-83.

Rosas, J. M., \& Callejas-Aguilera, J. E. (2006). Context switch effects on acquisition and extinction in human predictive learning. Journal of Experimental Psychology: Learning, Memory, and Cognition, 32, 461-474.

Rosas, J. M., \& Callejas-Aguilera, J. E. (2007). Acquisition of a conditioned taste aversion becomes context dependent when it is learned alter extinction. Quarterly Journal of Experimental Psychology, 60, 9-15.

Rosas, J. M., Callejas-Aguilera, J. E., Ramos-Álvarez, M. M., \& Abad, M. J. F. (2006). Revision of retrieval theory of forgetting: what does make information context-specific? International Journal of Psychology and Psychological Therapy, 6, 147-166.

Rosas, J. M., García-Gutiérrez, A., \& Callejas-Aguilera, J. E. (2006). Effects of context change upon retrieval of first and secondlearned information in human predictive learning. Psicológica, 27, 35-56.

Satterthwaite, F. E. (1946). An approximate distribution of the estimates of variance components. Biometrics Bulletin, 2, 110-114.

Sjödén, P., \& Archer, T. (1989). Taste-aversion conditioning: the role of contextual stimuli. In T. Archer \& L. G. Nilsson (Eds.), Aversion, avoidance, and anxiety perspectives on aversively motivated behavior (pp. 87-120). Hillsdale: Erlbaum.

Welch, B. L. (1938). The significance of the difference between two means when the population variances are unequal. Biometrika, 34, 29-35.

Williams, B. A., \& McDevitt, M. A. (2002). Inhibition and superconditioning. Psychological Science, 13, 454-459. 